\title{
AN EXPLORATORY NOTE ON INTERSTATE LIVING-COST DIFFERENTIALS
}

\author{
Richard J. Cebula*
}

In the United States, there exist enormous geographic living-cost differentials. However, although there are a few exceptions (Haworth and Rasmussen, 1973; Cobas, 1978; Cebula, 1980; Ostrosky, 1983; and Hogan, 1984), the literature has essentially failed to investigate the determinants of these living-cost differences.

The studies cited above all deal exclusively with living costs in SMSAs. Accordingly, in order to provide further insights, this very brief Note examines determinants of interstate living-cost differentials.

The model to be examined here is given by:

$$
\begin{aligned}
\mathrm{Pi}= & \mathrm{a}_{0}+\mathrm{a}_{1} \text { Deni }+\mathrm{a}_{2} \text { Inci }+\mathrm{a}_{3} \mathrm{Ri}+ \\
& \mathrm{a}_{4} \text { Urbi }+\mathrm{u}
\end{aligned}
$$

where $\mathrm{Pi}=$ measure of the average cost of living for a four-person family living on an intermediate budget in state $\mathrm{i}, 1977$.

Deni $=1977$ population density in state $i$, expresed as the number of persons per square mile.

Inci $=1977$ per capita income in state $i$.

$\mathrm{Ri}=$ a dummy variable indicating existence of right-to-work laws in state $\mathrm{i}[\mathrm{Ri}=1$ if such legislation exists and $\mathrm{Ri}=0$ otherwise].

Urbi $=$ percentage of state i's population residing in urban areas, 1977.

The living-cost data, variable $\mathrm{Pi}$, are taken from McMahon and Melton (1978) and are so constructed as to be geographically compatible. ${ }^{1}$ The remaining data were obtained from various issues of the Statistical Abstract of the United States.

\footnotetext{
*Professor of Economics, Emory University.
}

The expected signs on coefficients $a_{1}$ through $a_{3}$ are, as follows:

(2) $a_{1}>0, a_{2}>0, a_{3}<0$

These arguments follow directly from the analysis in several of the aforementioned papers, including Cebula (1980), Hogan (1984), and Ostrosky (1983). The variable Urbi is included in the analysis to control for the fact that the cost-of-living tends to be higher in urban areas than in rural areas. It follows that, ceteris paribus, the larger the percentage of a state's population living in urban areas, the higher the average cost-of-living in the state. Hence, we expect that:

(3) $a_{4}>0$

Clearly, while such a variable might be reasonably included in an analysis of states, it could not be reasonably included in an analysis of SMSAs. Finally, unlike the earlier studies by Cebula (1980) and Ostrosky (1984), a separate variable for the total population size (argued by these studies to measure "agglomeration economies") is not included here, since, among other things, it is so highly correlated $(+0.77)$ with the variable Deni.

The OLS estimate of equation (1) is given by:

(4) $\mathrm{Pi}=691.11+1.09446$ Deni + $(+2.48)$

$$
\begin{aligned}
& \begin{array}{l}
\left.0.034413 \text { Inci }-\begin{array}{l}
2042.3 \\
(+4.68)
\end{array} \mathrm{Ri}+2.047\right) \\
(+1.98)
\end{array} \\
& \text { Urbi, } \mathrm{R}^{2}=0.74, \overline{\mathrm{R}}^{2}=0.70, \mathrm{DF}=45
\end{aligned}
$$

where terms in parentheses are $t-$ values. The results in equation (4) indicate that state living-costs levels are an increasing function of population density, per capita income, and the percentage of the state's population residing in urban areas. In addition, the existence of rightto-work laws in a state appears to result in a lower cost of living. These results are reason- 
ably compatible with the earlier analyses of overall living costs for SMSAs, except obviously the result for the variable Urbi, which variable could not logically have been included in the earlier studies of SMSA living costs.

\section{FOOTNOTE}

${ }^{1}$ The living-cost data derived by McMahon and Melton are far from ideal. For one thing, the coefficients they estimate are for SMSA data, yet they plug in state values to estimate state coefficients. This may not in fact lead to bad estimates, but the point is that the technique is questionable. Also, they do not make any attempt to measure the standard error of the estimates, so we have no idea as to how accurate the estimates are. In any event, despite data imperfections, these state living-cost data are what we have to work with.

\section{REFERENCES}

Cebula, R. J. "Determinants of Geographic Living-Cost Differentials in the United States: An Empirical Note," Land Economics, 56, Nov., 1980, 476-81.

Cobas, J. A. "A Method to Estimate the Bureau of Labor Statistics Family Budgets for all Standard Metropolitan Statistical Areas," Social Science Quarterly, 59, Dec., 1978, 546-52.

Haworth, C. T. and D. W. Rasmussen. "Determinants of Metropolitan Cost of Living Variations," Southern Economic Journal, 40, Oct., 1973, 183-92.

Hogan, T. D. "Geographic Living-Cost Differentials in the United States: A Disaggregated View," Land Economics, 60, Feb., 1984, 115-9.

McMahon, W. and C. Melton. "Measuring Cost of Living Variation," Industrial Relations, 17, Oct., 1978, 324-32.

Ostrosky, A. L. "Determinants of Geographic Living-Cost Differentials in the United States: Comment," Land Economics, 59, Aug., 1983, 350-2. 